\title{
Improvement of Productivity in Metal Stamping Process of Ethiopian Industries Through Introducing CAD/CAM Based Press Tools
}

\author{
Kassahun Nigussie Asfew, Wassihun Yimer Amdie \\ Department of Mechanical Engineering, Adama Science and Technology University, Adama, Ethiopia
}

Email address:

kasmat16@gmail.com (K. N. Asfew), Wassihunyimer@yahoo.com (W. Y. Amdie)

\section{To cite this article:}

Kassahun Nigussie Asfew, Wassihun Yimer Amdie. Improvement of Productivity in Metal Stamping Process of Ethiopian Industries Through Introducing CAD/CAM Based Press Tools. International Journal of Industrial and Manufacturing Systems Engineering. Vol. 2, No. 3, 2017, pp. 19-23. doi: 10.11648/j.ijimse.20170203.11

Received: January 24, 2017; Accepted: March 1, 2017; Published: June 19, 2017

\begin{abstract}
Metal stamping is a sheet metal manufacturing process in which products are made using press machine and press tools. Currently sheet metal stamping process is practiced in Ethiopian metal industries in large amount but, mostly they use the technology which has been introduced to the companies 50 years back. This results in larger loss in material, economy and machines. These paper work asses the loss in the existing manufacturing process and provides a better way which conforms to the modern technology. In the existing metal stamping process of our country's metal industries large press machines are used with separate single operation press tools. But, in modern technology a progressive dies are used in which all the operations are integrated in one progressive press tool and all the operations are done successively. In this paper work a progressive press tool is designed using logopress 3 die design software for a part called receiver body which is produced in Gafat armament industry. In the existing system the part is produced after passing through 22 separate working stations, 48 parts are made per day and it costs 102 birr per part. But in the newly designed progressive press tool the part is produced in one progressive die, 7200 parts are produced per day and it costs 12.23 birr per part. Therefore, introducing modern progressive press tools using computer aided design/computer aided manufacturing software's could make a huge difference in Ethiopian metal industries.
\end{abstract}

Keywords: Progressive Die, Solidworks 2012, Logopress 3, Camworks 2012, Stamping, Nc Codes

\section{Introduction}

Metal stamping die is an ideal tool that can produce large quantities of parts that are consistent in appearance, quality and dimensional accuracy. Production stamping is generally performed on materials $0.5 \mathrm{~mm}$ to $2 \mathrm{~mm}$ thick, but the process also can be applied to foils as thin as $0.025 \mathrm{~mm}$ or to plate stock with thickness approaching $25.4 \mathrm{~mm}$ [1]. It's a press tool capable of cutting the sheet metal, bending, draw it into a considerable depths, embossing, coining, finishing the edges, curling or altering the shape and the outline of the metal part to suit the wildest imaginable design concepts [7].

Stamping is a cold-forming operation, which means that no heat is introduced into the die or the sheet material intentionally. However, because heat is generated from friction during the cutting and forming process, stamped parts often exit the dies very hot. A stamping die is a special, one-of-a-kind precision tool that cuts and forms sheet metal into a desired shape or profile. The die's cutting and forming sections typically are made from special types of hardenable steel called tool steel. Dies also can contain cutting and forming sections made from carbide or various other hard, wear-resistant materials. Dies range in size from those used to make microelectronics, which can fit in the palm of your hand, to those that are $20 \mathrm{ft}$. square and $10 \mathrm{ft}$. thick that are used to make entire automobile body sides. [9]

The decision to produce a part progressively is usually determined by two factors: the volume of production and the complexity of the part. These two factors are instrumental in the design and construction of the tooling. The process begins with determining how the part will be run through the die. This is governed by the features of the part and the locations of the datum's and critical tolerances. How parts are carried in the strip affects how well the die feeds, the ability to lift the strip for feeding, and the ability 
to produce consistent-quality parts. Three basic options are available for carrying a part, although many variations of each also can be used. In the most straightforward approach, parts are carried by the scrap between them. Excess material equal to one to two material thicknesses per side is required for trimming. This method typically produces minimal scrap. [10]

\subsection{Problem Statement}

Currently there are 3 major metal stamping industries in Ethiopia. They use the technology that introduced to the companies 25 years back by foreign companies and their production process is similar in many ways. In this study one case company is selected (Gafat armament industry) based on the largest number and type of products produced by metal stamping technology. Then one product is selected from the case company, based the largest number of operation done on the product. While we observe the overall production process the following problems has been identified:

a. The technologies are traditional, so that the production capacity and quality of the current production system don't fit the demand.

b. Currently Ethiopian metal company's uses separate dies for each sheet metal operations. This increases the production time for each product.

c. They lack dimensional accuracy and consistency. Thus mostly this result problem at the stage of assembling.

d. The processes have less raw material, machine and manpower utilization.

e. Modern press tools like progressive dies which produce quality and consistent parts with large amount are not yet introduced widely.

f. The above listed and other problems which are not listed here summed up and hurt the productivity of Ethiopian metal stamping industries.

\subsection{Objective}

The major objective of this paper work is 'to identify the root causes of the less productivity in Ethiopian metal stamping industries and proposes the possible directions of improvement.

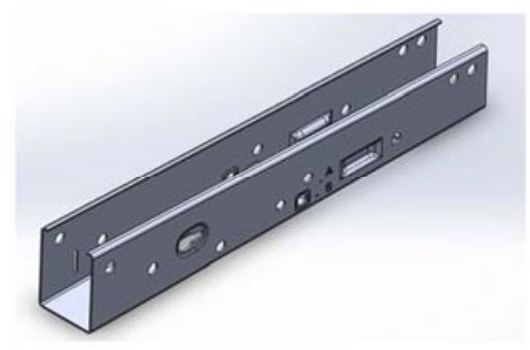

Figure 1. Model of a receiver body of ET 97/1 modeled Kalashnikov using SolidWorks 2012.

\subsection{Scrap Strip Layout}

The second step in designing a die is to layout the material

\section{Methodology}

This section presents the procedures that were taken in solving the problems that are identified. The researcher followed the following procedures in bringing a successful result in this paper work. The procedures are as listed as below:

\subsection{Literature Review and Data Collection}

1. Reviewing relevant past works and journals on press tool designing.

2. Reviewing different books that can guide me through selection of the proper material and proper designing of each part.

3. Collecting geometrical data's that can define the size, shape and additional descriptions about the receiver body from Gafat armament industry and using it as a basis for designing the progressive die with an appropriate strip layout.

4. Collecting different video tutorials and modules that can help in understanding CAD/CAM software's

\subsection{Designing a Press Tool and Simulation of Stamping Process}

1. Designing each die set parts with the appropriate way according to the handbooks of die design.

2. Modeling each part of the progressive die set and assembling by using solidworks 2012 software's.

3. Simulating the real process of the stamping by using logopress 3 die design software.

4. Generating a machining code for selected parts of press tool by CAM software packages for those parts which will be produced on $\mathrm{CNC}$ machines.

\section{Result and Discussion}

\subsection{Component Analysis}

Currently the case company (Gafat armament industry) produces this part using different manufacturing process like press working, machining and manual finishing operations. The first work of this paper work is to model the part using SolidWorks 2012 (sheet metal module) as indicated in the figure below:
Sheet metal specification
- Material: hot rolled steel AISI1020
- Thickness: $1.1 \mathrm{~mm}$
- Shear strength: $310 \mathrm{Mpa}$
- Supply condition: strips

strip exactly as it will appear after all operations have been performed [8]. It is called a scrap strip layout. The designing of the strip layout is done by grouping similar operations in 
one station. The total numbers of stations are seven as maximum area of the strip.

indicated in figure 2 the blank must be positioned so a

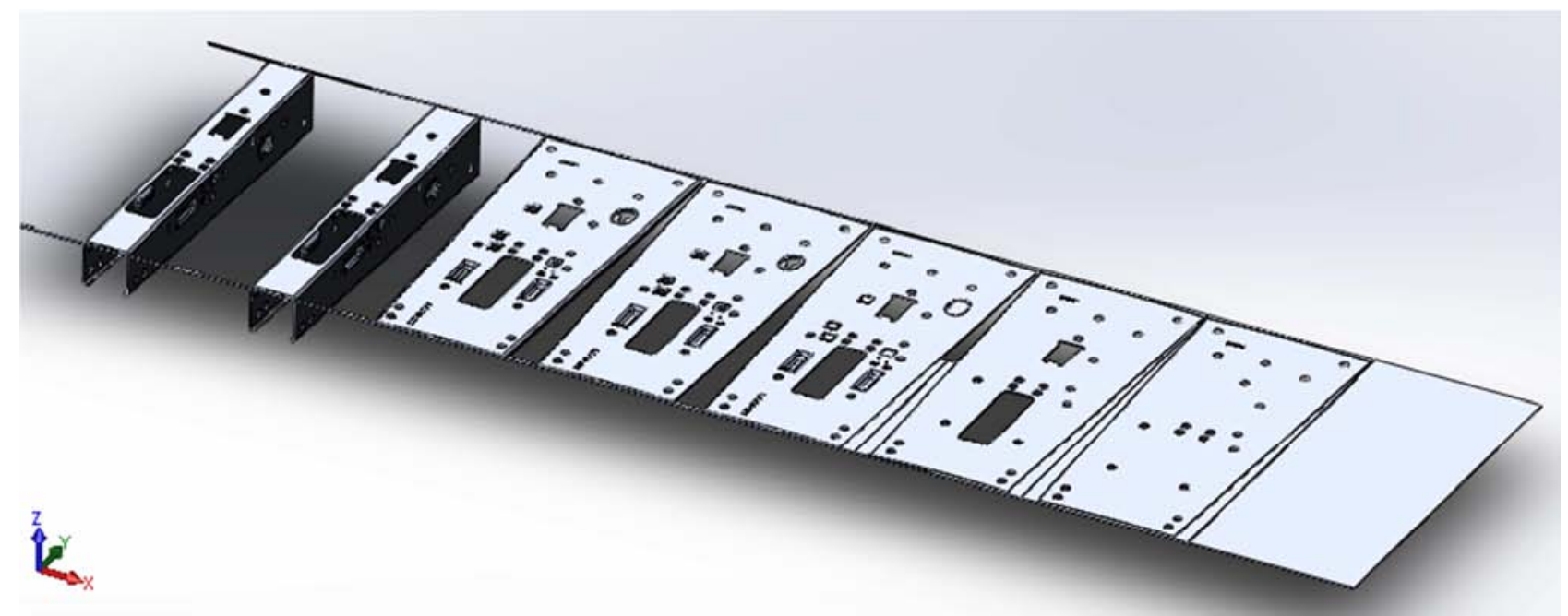

Figure 2. Isometric view of the scrap strip assembly using logopress 3.

The material utilization is calculated to be $88.1 \%$ (11.9\% material lost) therefore, the strip layout is efficient.

\subsection{Press Tonnage Calculation}

The total amount of pressure, or tonnage, needed for carrying out all die operations has to be determined. On the basis of this tonnage, the press tool components are designed. For all the operation different equations have been used. They are:

a. Cutting force $(\mathrm{F})$ can be calculated using the following equation [7]:

$$
K_{r} \text { : deformation resistance of the material (its } 110 \mathrm{~N} / \mathrm{mm}^{2} \text { ) }
$$

$A_{e}:$ punch area

c. tonnage for bending operation can be calculated as [7]:

$$
F_{\text {wipe }}=S * w * t^{2} / L
$$

Where: $S=$ the ultimate tensile strength of the material(its 394.72Mpa for AISI1020)

$$
\begin{gathered}
w=\text { width of the bent up portion } \\
L=\text { distance betwen two supports of the material }
\end{gathered}
$$

Using the above equations the total tonnage required for all the die operation on the seven stations is: 92.71 tone

\subsection{Design Calculations for Die Components}

\subsubsection{Punch Design}

The analysis is done for the smallest punch, which has $6 \mathrm{~mm}$ diameter and length of $80 \mathrm{~mm}$.

a. The mean compression strength is: $S_{M C}=227.38 \mathrm{~N} / \mathrm{mm}^{2}<3841 \mathrm{Mpa}$

b. Deflection of this piercing punch is given as: $\boldsymbol{\delta}_{P}=0.069 \mathrm{~mm}<0.08 \mathrm{~mm}$

\subsubsection{Bottom Bolster (Die Shoe)}

a. The deflection can be found from: $d=0.0175 \mathrm{~mm}<0.025 \mathrm{~mm}$

b. Stress, can be calculated as: $\sigma=9.816 * 10^{6} \mathrm{~N} / \mathrm{m}^{2}=9.816 \mathrm{Mpa}<250 \mathrm{Mpa}$ 


\subsubsection{Guide Posts and Guide Bushings}

a. Using Johansson equation the critical load is: $P_{c r}=2564.6 M N>180.8 \mathrm{KN}$

b. deflection of the pillar is given by: $\boldsymbol{\delta}_{P}=0.072 \mathrm{~mm}<0.08 \mathrm{~mm}$

c. Stress can be calculated as: $\sigma=9.21 * 10^{7} \mathrm{~N} / \mathrm{m}^{2}=92.1 \mathrm{Mpa}<250 \mathrm{Mpa}$

\subsubsection{Upper Portion Plate Set}

a. The deflection can be calculated as: $\delta=0.067 \mathrm{~mm}<0.08 \mathrm{~mm}$

b. Stress, can be calculated as: $\sigma=6.89 * 10^{6} \mathrm{~N} / \mathrm{m}^{2}<250 \mathrm{Mpa}$

\subsection{FEM (Finite Element Method) Based Analysis}

The boundary a condition for parts listed below is one end fixed and the other is free and the load is exerted on is free end.

\subsubsection{Analysis for the Smallest Piercing Punch}

Material: D2 tool steel; P (applied load) $=6424.44 \mathrm{~N}$

Table 1. Analysis results for the smallest piercing punch.

\begin{tabular}{|c|c|c|c|c|c|c|}
\hline \multirow{2}{*}{$\begin{array}{l}\text { Part Name } \\
\text { The smallest punch }\end{array}$} & \multicolumn{2}{|l|}{ Von Misses Stress } & \multicolumn{2}{|c|}{ Resultant Displacement } & \multicolumn{2}{|c|}{ Equivalent Strain } \\
\hline & Min, N/mm ${ }^{2}$ (Mpa) & $\operatorname{Max}, \mathbf{N} / \mathbf{m m}^{2}$ (Mpa) & Min, $\mathbf{m m}$ & Max, mm & Min & $\operatorname{Max}$ \\
\hline & 8.42 & 237 & 0 & 0.0312721 & $3.66457 \mathrm{e}-005$ & 0.000939026 \\
\hline Yield strength & \multicolumn{6}{|c|}{$2,200 \mathrm{~N} / \mathrm{mm}^{2} \mathrm{~F}=6424.44 \mathrm{~N}$} \\
\hline
\end{tabular}
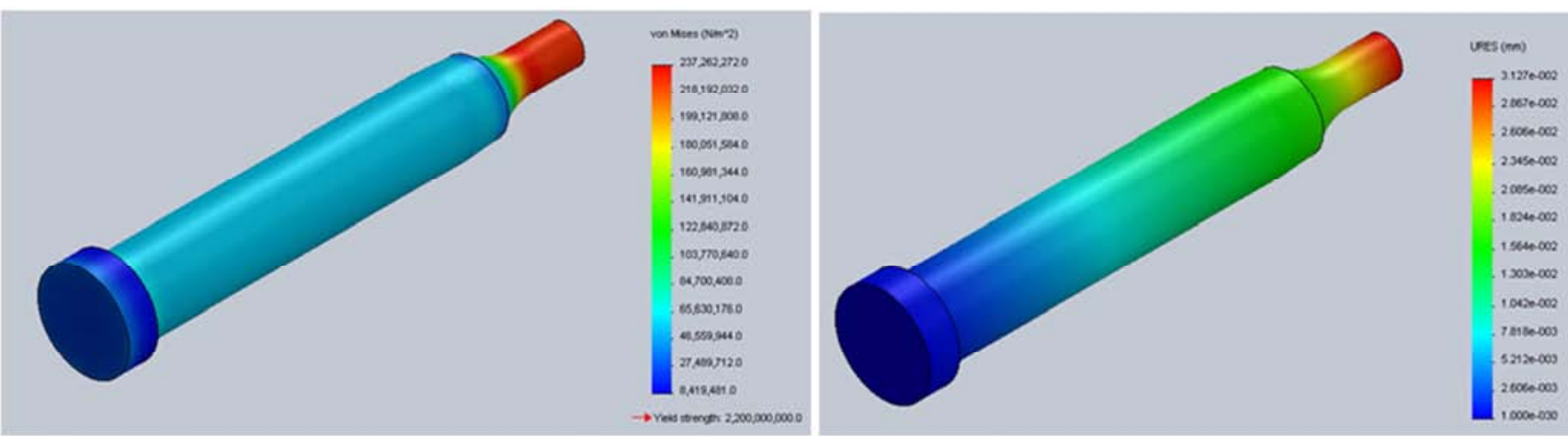

Figure 3. Stress and displacement result for smallest piercing punch.

\subsubsection{Analysis for the Smallest Embossing Punch}

Material: S7 tool steel; P (applied load) $=10111 \mathrm{~N}$

Table 2. Analysis result for the smallest embossing punch

\begin{tabular}{|c|c|c|c|c|c|c|}
\hline \multirow{2}{*}{$\begin{array}{l}\text { Part Name } \\
\text { The smallest punch }\end{array}$} & \multicolumn{2}{|l|}{ Von Misses Stress } & \multicolumn{2}{|c|}{ Resultant Displacement } & \multicolumn{2}{|c|}{ Equivalent Strain } \\
\hline & Min, N/mm ${ }^{2}$ (Mpa) & Max, N/mm² (Mpa) & Min, $\mathbf{m m}$ & Max, mm & Min & Max \\
\hline & 3.81 & 182.3 & 0 & 0.0413633 & $4.07486 \mathrm{e}-005$ & 0.000750246 \\
\hline Yield strength & $1,450 \mathrm{~N} / \mathrm{mm}^{2} \mathrm{~F}=1011$ & & & & & \\
\hline
\end{tabular}
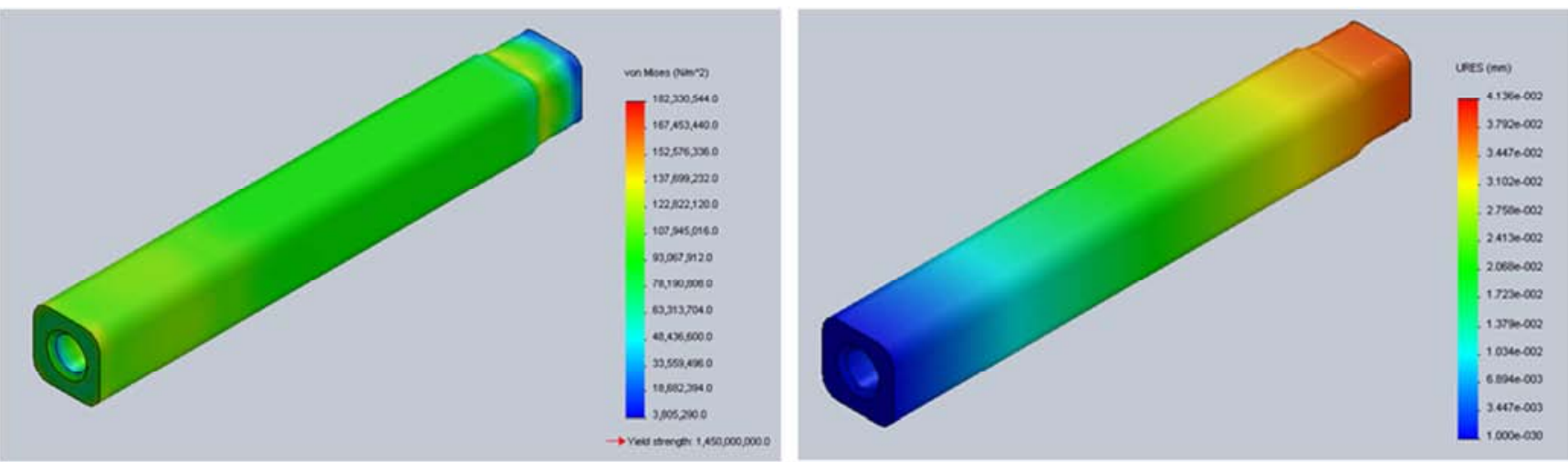

Figure 4. Stress, strain and displacement result for the smallest embossing punch. 


\subsection{Payback Period Analysis}

a. The calculated value of the payback period is: 5 months with 10 days.

\subsection{Gap Descriptions}

The gap description between the existing and improved system is made by comparing the improvements in terms of:

a. cost per part

b. manufacturing process

\subsubsection{Gap Description in Terms of Cost}

a. Improved from 105 birr to 12.23 birr per part.

\subsubsection{Gap Description in Terms of Manufacturing Process}

Table 3. Gap description in terms of manufacturing process.

\begin{tabular}{|c|c|}
\hline The existing system & The improved system \\
\hline $\begin{array}{l}\text { The part passes through } 22 \\
\text { manufacturing processes. }\end{array}$ & $\begin{array}{l}\text { All are integrated together in one } \\
\text { progressive die. }\end{array}$ \\
\hline $\begin{array}{l}\text { It uses } 11 \text { press machines, five table } \\
\text { drilling machine and one portable } \\
\text { drill. }\end{array}$ & It uses only one 250 tone press. \\
\hline It uses 11 die set. & It uses \\
\hline The & The material utilization is $88.2 \%$ \\
\hline $\begin{array}{l}\text { The blank is first bent and other press } \\
\text { and machining operations are done on } \\
\text { the bent part. }\end{array}$ & $\begin{array}{l}\text { All the operations are done on the } \\
\text { flat sheet and finally it will be bent. }\end{array}$ \\
\hline s 7 auxilia & $\begin{array}{l}\text { It needs only on buff grinding and } \\
\text { one stage washing and cleaning. }\end{array}$ \\
\hline 48 parts are made per day & 7200 parts are made per day \\
\hline
\end{tabular}

\section{Conclusion}

Following fundamental principles and procedure in the progressive die designing area, every possible effort has been made in designing a progressive die that meets the functional requirements. Powerful and important engineering software's such as logopress 3, Solidworks 2012 simulation Xpress module and Camworks 2012 have been used for designing and simulation, analysis and machining code generation respectively. Many improvements are made by designing the progressive die. These are: 22 manufacturing operation has replaced by one press operation resulting in cost reduction and improvement in accuracy and consistency. Therefore, introducing $\mathrm{CAD} / \mathrm{CAM}$ based press tools to Ethiopian metal stamping industries could result in a huge improvements.

\section{References}

[1] Ch. Mastanamma, K. Prasada Rao, Dr. M. Venkateswara Rao; International Journal of Engineering Research \& Technology (IJERT) Vol. 1 Issue 6, August - 2012.

[2] Cyril Donaldson, George H Le Cain, VC Goold, Tool Design, $3^{\text {rd }}$ edition, Tata McGraw Hill.

[3] David T. Reid, Fundamentals of Tool Design, 3rd edition, Society of Manufacturing Engineers (SME).

[4] D. Eugene Ostergaard, Basic Die making, committee of the national tooling and Machining association, (C) 1963 McGraw -Hill Book Company.

[5] Dr. AndriAndriyana, Failure Criteria for Yielding; Paris, 06904 Sophia Antipolis, France Spring, 2008.

[6] George Roberts, George Krauss, Richard Kennedy, Tool Steel, $5^{\text {th }}$ edition, (C) ASMinternational.

[7] Ivana Suchy: Handbook of Die Design, Second Edition. METAL STAMPING DIES AND THEIR FUNCTION, Chapter (McGraw-Hill Professional, 2006 1998), Access Engineering.

[8] J R Paquin, R E Crowley, Die design fundamentals, New York, N. Y.: Industrial Press, (C)1987.

[9] The fabricator.com, [APRIL 11, 2005], Die Basics 101. Retrieved from http://www.thefabricator.com/article/stamping/die-basics-101part-i

[10] Michael Korneli, designing progressive dies, stamping journal January/February 1999. 